\title{
Therapeutic effects of Hedyotis diffusa Willd in a COPD mouse model challenged with LPS and smoke
}

\author{
RENPING LIU ${ }^{1}$, PEIHONG WANG ${ }^{1}$, CAIQING WU ${ }^{1}$, JUAN CHEN $^{1}$, CHENGXIN LI $^{1}$, \\ YONGTAO XIE ${ }^{1}$, QI WANG ${ }^{1}$, JIANMING LIU ${ }^{2}$, HUAN HE $^{3}$ and JING ZHU ${ }^{1}$ \\ ${ }^{1}$ Medical Experiment Education Department, Medical College of Nanchang University, Nanchang, Jiangxi 330031; \\ ${ }^{2}$ Department of Pharmacology, Jiangxi Medical College, Shangrao, Jiangxi 334000; \\ ${ }^{3}$ Department of Pharmacology, Fuzhou Medical College of Nanchang University, Fuzhou, Fujian 344000, P.R. China
}

Received April 28, 2017; Accepted January 10, 2018

DOI: $10.3892 /$ etm.2018.5851

\begin{abstract}
Hedyotis diffusa Willd (HDW) is a constituent of several Chinese medicines used clinically to treat inflammatory diseases, including airway inflammation. The aim of the present study was to investigate whether HDW serves a protective role in suppressing chronic airway inflammation and its underlying mechanisms. A mouse model of chronic smoking was induced via exposure to cigarette smoke (CS) for 30 days, increasing the exposure time for up to $5 \mathrm{~min}$ per day and the administration of lipopolysaccharide (LPS). Mice were gavaged with HDW (50 or $100 \mathrm{mg} / \mathrm{kg}$ body weight), dexamethasone (1 $\mathrm{mg} / \mathrm{kg}$ body weight) or normal saline (NS, 0.9\%) $1 \mathrm{~h}$ prior to CS challenge. Compared with CS and LPS (SL)-induced mice, the levels of interleukin (IL)-1 $\beta$, tumor necrosis factor- $\alpha$ and transforming growth factor- $\beta$ in bronchoalveolar lavage fluid from HDW+SL mice were significantly decreased and IL-10 was markedly reduced. Histological examination of the lung tissues revealed that HDW treatment alleviates airway inflammation. In addition, the administration of HDW to human bronchial epithelial BEAS-2B cells suppressed the activity of the nuclear factor $(\mathrm{NF})-\kappa \mathrm{B}$ signaling pathway. The results of the present study demonstrate that HDW has a therapeutic effect in COPD and the underlying mechanism may be attributed to inhibition of the $\mathrm{NF}-\kappa \mathrm{B}$ pathway.
\end{abstract}

Correspondence to: Dr Renping Liu, Medical Experiment Education Department, Medical College of Nanchang University, 999 Xuefu Road, Nanchang, Jiangxi 330031, P.R. China

E-mail: sirlrp@163.com

Abbreviations: DEX, dexamethasone; BALF, bronchoalveolar lavage fluid; CS, cigarette smoke; HDW, Hedyotis diffusa Willd; SL, cigarette smoke+lipopolysaccharide

Key words: chronic obstructive pulmonary disease, Hedyotis diffusa Willd, nuclear factor- $\kappa \mathrm{B}$, airway inflammation

\section{Introduction}

It is predicted that chronic obstructive pulmonary disease (COPD), one of the major causes of morbidity and mortality worldwide, will be the third leading cause of death by 2030 (1). COPD is characterized by progressive airflow obstruction and pulmonary inflammation, typically the result of repeated exposure to cigarette smoke (CS) and lipopolysaccharide (LPS), an important endotoxin of gram-negative bacteria (2).

The pathophysiology of COPD involves the infiltration of multiple inflammatory cells, including macrophages, neutrophils and Tlymphocytes (3). Cytokines are the key orchestrators of chronic inflammatory diseases and at least 50 cytokines have thus far been reported to be associated with COPD (4). Interleukin-1 $\beta$ (IL-1 $\beta$ ) is a proinflammatory cytokine that is able to activate macrophages in patients with COPD to release inflammatory cytokines, chemokines and matrix metalloproteinase 9 (5). Tumor necrosis factor (TNF)- $\alpha$ secreted by macrophages is an important cytokine in the innate immune response, which protects against invading organisms prior to activation of the adaptive immune system (6). Dysregulation of the TNF- $\alpha$ response is associated with several inflammatory diseases (7). Transforming growth factor (TGF)- $\beta$ is a multifunctional growth factor that is generated from a latent precursor via stress-activated responses (8). It facilitates the proliferation of fibroblasts and airway smooth muscle cells, deposition of extracellular matrix and epithelial repair (8). In addition, it has immune regulatory actions that are mainly mediated by regulatory $\mathrm{T}$ (Treg) cells (9). Treg cells suppress the immune system partially via the secretion of IL-10 (9). A previous study indicated that an increase in the IL-17A/IL-10 ratio in mice exposed to chronic CS may be associated with immune self-tolerance in COPD (10).

Nuclear factor $-\kappa \mathrm{B}(\mathrm{NF}-\kappa \mathrm{B})$ is an indispensable protein transcription factor for the many important proinflammatory molecules, including critical enzymes (cyclooxygenase- 2 and inducible nitric oxide synthase) and most cytokines (IL-1 $\beta$, IL-6 and TNF- $\alpha$ ) $(6,11)$. NF- $\kappa$ B is activated when it is phosphorylated by inhibitor of NF- $\kappa \mathrm{B}(\mathrm{I} \kappa \mathrm{B})$ kinase and dissociates from $I \kappa B \alpha(6)$. NF- $\kappa B$ then translocates to the nucleus for further gene transcription via binding to the promoter of $\mathrm{NF}-\kappa \mathrm{B}-$ responsive genes. 
Hedyotis diffusa Willd (HDW), a traditional Chinese herb, contains many chemicals, including triterpenoids, ferulic acid, sterols, iridoid glycosides, polypeptides, flavonoids, ursolic acids, oleanolic acids and polysaccharides, some of which have anti-inflammatory or antioxidative effects (12). Due to its antibacterial activity, it is extensively employed to treat inflammatory diseases, including appendicitis and bronchitis (12). However, thus far there have been few studies clearly demonstrating the anti-inflammatory mechanisms of HDW in COPD. In the present study, it was demonstrated that HDW exhibits a powerful anti-inflammatory ability by inhibiting the NF- $\kappa \mathrm{B}$ signaling pathway, indicating that HDW has the potential to treat airway inflammation diseases.

\section{Materials and methods}

Plant material, extraction and isolation, high performance liquid chromatography-mass spectrometry (HPLC-MS) analysis. HDW was collected in Zhangshu (China) in September 2015 and identified by Professor Lai from the Medical College of Nanchang University (Nanchang, China). A voucher specimen (no. 20150910A) was deposited at the Natural Product Laboratory of the Medical Experiment Education Department, Medical College of Nanchang University. Fresh HDW leaves and stems $(2.5 \mathrm{~kg})$ were cut into very small pieces $(\sim 6 \mathrm{~mm})$ and extracted with 251 of $85 \%$ ethanol using a refluxing and filtering method (13). The ethanol solvent of the filtrate was evaporated using a rotary evaporator (Shanghai Yarong Biochemistry Instrument Factory, Shanghai, China). The resultant solution was concentrated to a relative density of 1.05 and a dry powder was obtained using a spray drying method at $40^{\circ} \mathrm{C}$ for $2 \mathrm{~h} \mathrm{(14).}$

The HDW powder was dissolved in dimethyl sulfoxide (DMSO) and the final concentration of DMSO was adjusted to $0.1 \%(\mathrm{v} / \mathrm{v})$ in Roswell Park Memorial Institute 1640 culture medium (Beijing Solarbio Science \& Technology Co., Ltd., Beijing, China). DMSO alone served as a control in all cases.

A Shimadzu (Kyoto, Japan) 30A series HPLC-MS instrument was used for HPLC. Chromatographic separation was performed on a Shim-pack Gist $\mathrm{C}_{18} \times 2 \mu \mathrm{m}$ column $(75 \times 2.1 \mathrm{~mm}$; Shimadzu) at $35^{\circ} \mathrm{C}$ using a column oven. Methanol and water with $0.05 \%$ acetic acid were used as the mobile phases. The injection volume was $5 \mu \mathrm{l}$ and the flow rate was $0.2 \mathrm{ml} / \mathrm{min}$.

For HPLC-MS, the detector of an AB SCIEX (Framingham, MA, USA) Triple TOF5600 instrument was set to an electrospray ion source with negative polarity ionization. The scanning range was $m / z, 80-800$. The HPLC-MS results revealed that the components of the ethanol fraction of HDW contained ferulic, oleanolic and ursolic acids. The observed relative retention time for oleanolic and ursolic acids was $20.77 \mathrm{~min}$ and was $4.83 \mathrm{~min}$ for ferulic acids (Fig. 1).

Reagents. ELISA kits for IL-1 $\beta$ (cat. no. 432604), TNF- $\alpha$ (cat. no. 430904), TGF- $\beta$ (cat. no. 433007) and IL-10 (cat. no. 431414) were obtained from Biolegend Systems (San Diego, CA, USA). The ELISA kits were used according to the manufacturers' protocol. Rabbit anti-mouse IgG primary antibodies

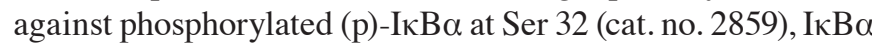
(cat. no. 4812), p65 (cat. no. 8242), Lamin B (cat. no. 13435) and $\beta$-actin (cat. no. 4967) were obtained from Cell Signaling
Technology, Inc. (Danvers, MA, USA). Secondary antibody (horseradish peroxidase-conjugated goat anti-rabbit IgG; cat. no. sc-2004) was obtained from Santa Cruz Biotechnology, Inc. (Dallas, TX, USA). Dexamethasone was obtained from Shanghai Xinyi Pharmaceutical Co., Ltd. (Shanghai, China) and Lushan cigarettes were obtained from Jiangxi Tobacco (Nanchang, China).

Culture and induction of BEAS-2B cells. BEAS-2B cells obtained from the Center of Cells, Suzhou University (Suzhou, China) were grown in Eagle's minimum essential medium (Beijing Solarbio Science \& Technology Co., Ltd.) supplemented with $10 \%$ fetal bovine serum (Beijing Transgen Biotech Co., Ltd., Beijing, China), 2 mmol/1 L-glutamine, 100 units $/ \mathrm{ml}$ penicillin and $100 \mu \mathrm{g} / \mathrm{ml}$ streptomycin in a humidified atmosphere of $5 \% \mathrm{CO}_{2}$ at $37^{\circ} \mathrm{C}$ for 4 days.

The BEAS-2B cells were plated on a $35-\mathrm{mm}$ dish $\left(5 \times 10^{3}\right.$ cells $\left./ \mu 1\right)$ and incubated overnight in complete growth medium as aforementioned. The cells were incubated with 20, 10,1 or $0.1 \mu \mathrm{mol} / 1 \mathrm{HDW}$ or DMSO for $1 \mathrm{~h}$, followed by treatment with LPS $(10 \mu \mathrm{g} / \mathrm{ml})$ or D-Hanks for $30 \mathrm{~min}$ (for the phosphorylation and degradation of $\mathrm{I} \kappa \mathrm{B} \alpha$ ) or $24 \mathrm{~h}$ (for the level of nuclear $\mathrm{NF}-\kappa \mathrm{B} / \mathrm{p} 65)$, respectively.

Western blotting. Nuclear and total proteins were collected from the cultured cells using the Nuclear and Cytoplasmic Proteins Extraction kit (Applygen Technologies Inc., Beijing, China) according to the manufacturer's protocol. Supernatants were assayed for protein content using a BCA Protein Assay kit (Beijing Solarbio Science \& Technology Co., Ltd.). Cell lysates $(40 \mathrm{mg}$ ) were separated by $10 \%$ SDS-PAGE and transferred onto nitrocellulose acetate membranes. Following blocking with 5\% nonfat dry milk (Bio-Rad Laboratories, Inc., Hercules, CA, USA) in TBS-T buffer (20 mM Tris base, $150 \mathrm{mM} \mathrm{NaCl}$ and $0.1 \%$ Tween-20) for $2 \mathrm{~h}$ at room temperature. Membranes were blotted with primary antibodies in TBS-T buffer (1:1,000; phospho-I $\kappa \mathrm{B} \alpha, \mathrm{I} \kappa \mathrm{B} \alpha$, p65, Lamin B and $\beta$-actin) overnight at $4^{\circ} \mathrm{C}$ and were subsequently incubated with horseradish peroxidase-conjugated secondary goat $\mathrm{IgG}$ (1:2,500 dilution) for $1 \mathrm{~h}$ at room temperature. Bands were visualized using an ECL Advance Western Blotting Detection kit (Tiangen Biotech Co., Ltd., Beijing, China) using a chemiluminescence detector (LAS 4000 mini; GE Healthcare Life Sciences, Little Chalfont, UK).

Cell proliferation assay. BEAS-2B cells were seeded in 96-well plates $\left(100 \mu \mathrm{l} ; 5 \times 10^{3}\right.$ cells $\left./ \mu \mathrm{l}\right)$ and allowed to attach overnight prior to treatment with $\operatorname{HDW}(0,0.1,1,10 \mu \mathrm{mol} / \mathrm{l})$ at $37^{\circ} \mathrm{C}$ for $24 \mathrm{~h}$. Cell Counting Kit-8 (CCK8; Beyotime Institute of Biotechnology, Haimen, China) reagent was added into each well and incubated at $37^{\circ} \mathrm{C}$ for $2 \mathrm{~h}$. The Optical density (OD) at $490 \mathrm{~nm}$ was recorded using a microculture plate reader. The cell growth inhibition rate was calculated as follows: $\left(\mathrm{OD}_{\text {control }}-\mathrm{OD}_{\mathrm{HDW}}\right) / \mathrm{OD}_{\text {control }} \mathrm{x} 100$.

Animals and cigarette smoke-induced pulmonary inflammation. A total of 75 adult male Kunming mice (age, 6-8 weeks; 18-20 g) were obtained from the Animal Center of Nanchang University and housed at $24 \pm 1^{\circ} \mathrm{C}$ with $50 \%$ relative humidity under a $12 \mathrm{~h}$ light/dark cycle and were allowed free access to 

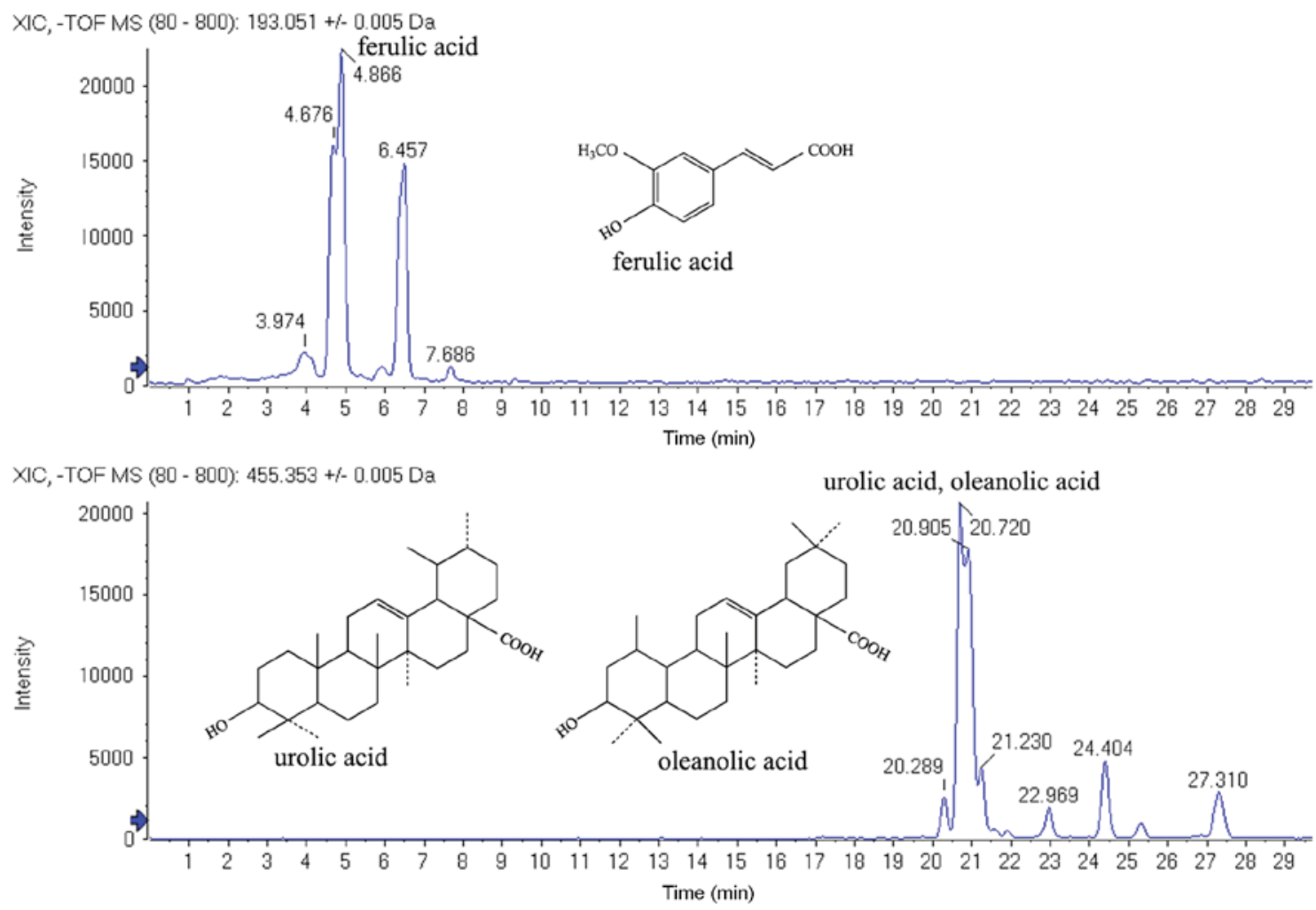

Figure 1. High performance liquid chromatography-mass spectrometry extracted ion chromatograms of ferulic, oleanolic and ursolic acids.

standard mouse food and water in environmentally controlled pathogen-free conditions during the experiments. All protocols were approved by the Institutional Animal Experimental Ethics Committee of Nanchang University.

The method used to establish the cigarette smoke-induced COPD animal model was adapted from Chen et al (2). Mice were randomly divided into 5 groups (each $n=15)$ : A saline-treated group, a cigarette smoke+lipopolysaccharide (SL)-challenged group, an SL+HDW (50 mg/kg)-treated group, an SL+HDW (100 mg/kg)-treated group and a dexamethasone-treated group. Except for the saline-treated group, mice in other groups were challenged with CS in a 41 homemade Plexiglas container for $5 \mathrm{~min} /$ day for 30 days and were infused with $20 \mu \mathrm{g}$ of LPS in $30 \mu \mathrm{l}$ of normal saline on days 1 and 14. For the SL+HDW (50 mg/kg)-treated, SL+HDW (100 mg/kg)-treated and dexamethasone-treated groups, mice were respectively gavaged with HDW (100 mg/kg body weight) and dexamethasone ( $1 \mathrm{mg} / \mathrm{kg}$ body weight) $1 \mathrm{~h}$ prior to CS challenges for 1 week. At $24 \mathrm{~h}$ following the final administration of HDW, mice were weighed and sacrificed. The weight of thymus and spleen was then assessed in each group.

Bronchoalveolar lavage fluid (BALF) analysis. Mouse tracheas were surgically exposed and cannulated with a blunt 20 -gauge needle. BALF was obtained by injecting 3 sequential 1-ml aliquots of PBS and withdrawing as much fluid as possible, following which the BALF was pooled. Cell suspensions in BALF were centrifuged at a speed of $700 \mathrm{x} \mathrm{g}$ for $10 \mathrm{~min}$ at $4^{\circ} \mathrm{C}$ and the supernatants were collected and stored at $-80^{\circ} \mathrm{C}$ for cytokine assays. Cytokine levels (IL- $1 \beta$, TNF- $\alpha$, TGF- $\beta$ and IL-10) in the BALF were measured using ELISA kits according to the manufacturer's protocol. The detection limit for each assay was $5 \mathrm{pg} / \mathrm{ml}$. Cells were resuspended in $300 \mu \mathrm{l}$ of $0.1 \%$ BSA/PBS (Beijing Solarbio Science \& Technology Co., Ltd.). Absolute cell counts were determined using a MEK-7222k automatic hematology analyzer (Nihon Kohden, Tokyo, Japan).

Lung histology. The lung histology was analyzed as previously described (2). The right lungs of mice from each group were fixed in a solution of $4 \%$ buffered formalin for 1 week at room temperature. Sections $3 \mu \mathrm{m}$ thick were deparaffinized by immersing in xylene followed by dehydratation in ethanol. Following a 5 min wash with PBS three times, sections were stained with a hematoxylin solution at room temperature for 5 min. After a 5 min wash with PBS three times, sections were stained with eosin solution at room temperature for $5 \mathrm{~min}$. A morphometric quantification of the stained lung sections was performed using a customized digital image processing system. Infiltrated airway inflammatory cells contain abundant cytoplasmic particles and based on images of the H\&E-stained lungs, the severity of peri-bronchial inflammation was recorded semiquantitatively as previously described: 0 , no inflammatory cells; 1 , a few inflammatory cells; 2 , a ring of inflammatory cells 1 cell-layer deep; 3 , a ring of inflammatory cells 2 cells deep; 4 , a ring of inflammatory cells 3-4 cells deep; and 5, a ring of inflammatory cells $>4$ cells deep.

The slides were examined and scored by a pathologist who was blinded to the treatment. The stained cell images were assessed at x10 and x20 magnification with a light Olympus VS120-S5-W whole-slide imaging system (Olympus Corporation, Tokyo, Japan). A total of six bronchioles were randomly evaluated in each slide and the average inflammation scores were calculated. 


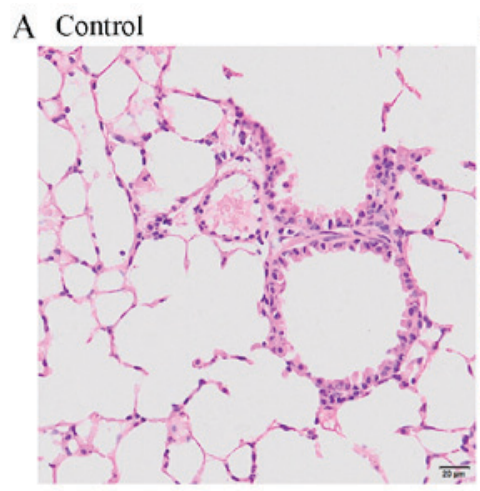

SL
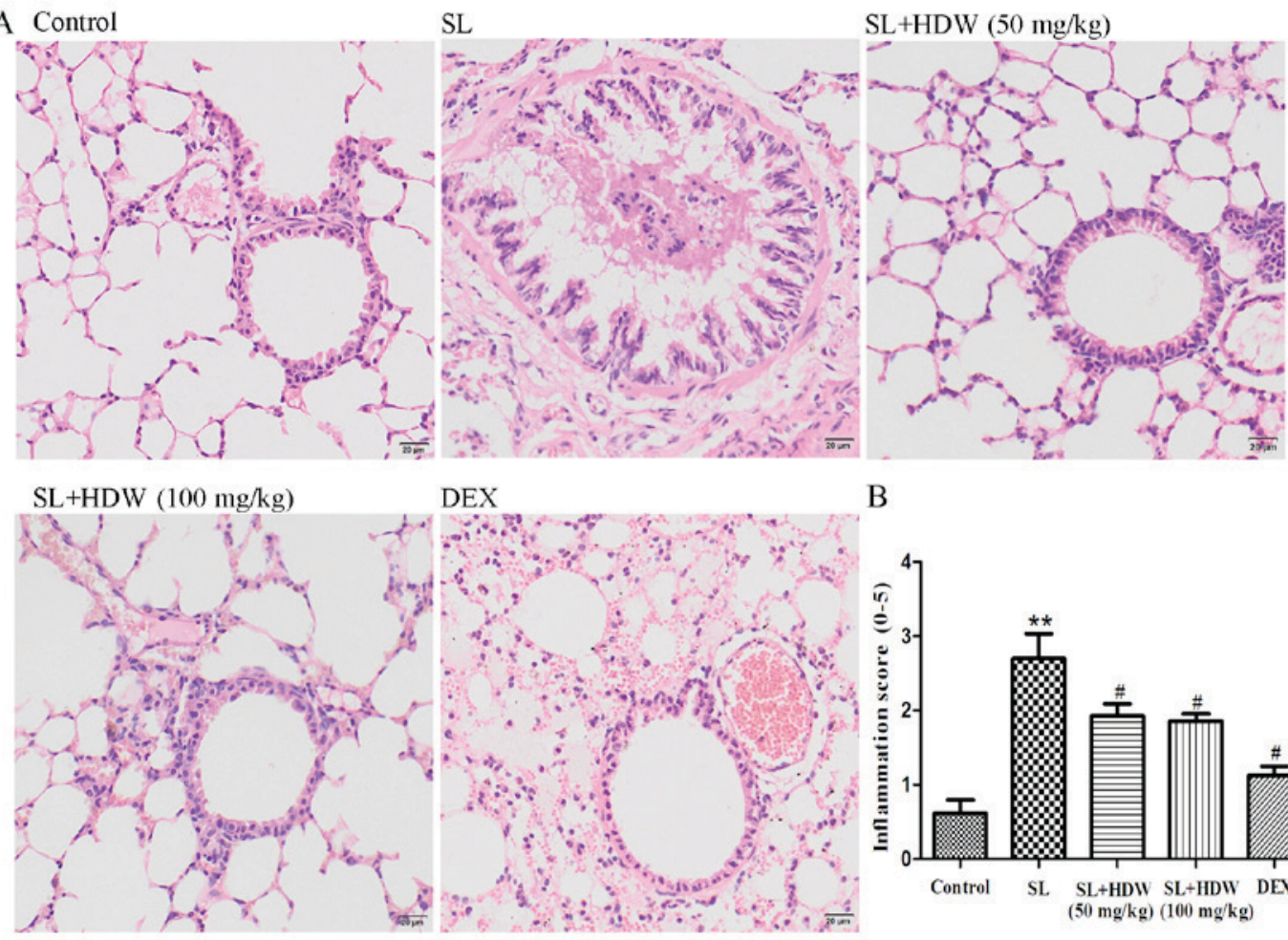

B

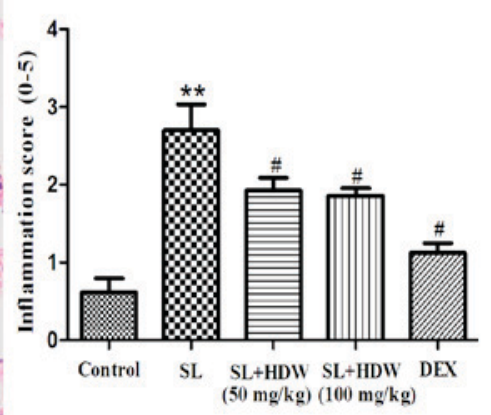

Figure 2. Effects of HDW on airway inflammation in a mouse model of chronic obstructive pulmonary disease. (A) Histological examination of mouse lung ( $\mathrm{n}=6$ per group) was performed $24 \mathrm{~h}$ following final SL stimulus. Formalin-fixed lung tissues were sectioned at a thickness of $3 \mu \mathrm{m}$ and stained with hematoxylin and eosin. (B) Semiquantitative scoring of airway inflammation. Magnification, $\mathrm{x} 200 .{ }^{* * *} \mathrm{P}<0.01$ vs. control and ${ }^{*} \mathrm{P}<0.05$ vs. SL. Control, saline-treated mice; SL, cigarette smoke+lipopolysaccharide-challenged mice; HDW, Hedyotis diffusa Willd; DEX, dexamethasone (1 mg/kg).

Statistical analysis. All experiments were performed at least three times. All values are expressed as the mean \pm standard error of the mean. One-way analysis of variance with Tukey's post hoc test was used to compare results. All data were analyzed using SPSS 17.0 (SPSS, Inc., Chicago, IL, USA). $\mathrm{P}<0.05$ was considered to indicate a statistically significant difference.

\section{Results}

Effects of HDW on airway inflammation in mice. To clarify the possible anti-inflammatory effects of HDW, lung tissues were isolated from mice $24 \mathrm{~h}$ following the final CS challenge. Lung tissue sections were stained with H\&E. Compared with the control group the mice challenged with SL for 30 days had significantly increased pulmonary inflammation ( $\mathrm{P}<0.01$; Fig. 2). In the SL+HDW $(50 \mathrm{mg} / \mathrm{kg}$ and $100 \mathrm{mg} / \mathrm{kg}$ ) mice, pulmonary inflammation was significantly lower compared with in the SL-treated mice ( $\mathrm{P}<0.05$; Fig. 2). The treatment of SL-challenged mice with dexamethasone inhibited pulmonary inflammation $(\mathrm{P}<0.05$; Fig. 2). However, the potent side effects of dexamethasone resulted in a decrease in murine spleen weight and size and body weight and the thymus markedly decreased in size in certain mice (data not shown). In the SL+dexamethasone group, $5 / 15$ mice succumbed during the whole experimental period.

Effects of HDW on inflammatory cells in BALF. To determine the effect of HDW on inflammatory cells in SL-induced mice, BALF was harvested $24 \mathrm{~h}$ following the last CS challenge. BALF from mice in the CS group had a higher number of total white blood cells (Fig. 3A), neutrophils ( $\mathrm{P}<0.05$; Fig. 3B), eosinophils (Fig. 3C) and macrophages (Fig. 3D). In the $\mathrm{SL}+\mathrm{HDW}(50 \mathrm{mg} / \mathrm{kg})$ group, the number of inflammatory cells was markedly decreased compared with the CS group (Fig. 3). Treatment with $100 \mathrm{mg} / \mathrm{kg}$ HDW significantly ameliorated the CS-induced increase in neutrophils in the BALF $(\mathrm{P}<0.05$; Fig. 3B).

Effect of HDW on cytokine levels in BALF. To evaluate the effects of HDW on cytokine levels in the a COPD mouse model, ELISA kits were used to measure IL-1 $\beta$, TNF- $\alpha$, TGF- $\beta$ and IL-10 expression in the BALF. Levels of IL-1 $\beta$, TNF- $\alpha$ and TGF- $\beta$ were significantly elevated in the CS group compared with the control $(\mathrm{P}<0.05$; Fig. $4 \mathrm{~A}-\mathrm{C})$ and induced a marked increase in IL-10 expression (Fig. 4D). Treatment with $50 \mathrm{mg} / \mathrm{kg}$ HDW significantly inhibited the CS-induced increase in TNF- $\alpha$ and TGF- $\beta$ ( $\mathrm{P}<0.05$; Fig. $4 \mathrm{~B}$ and $\mathrm{C})$, whereas $100 \mathrm{mg} / \mathrm{kg}$ also caused a significant decrease in IL-1 $\beta$ (Fig. 4A).

Effect of HDW on BEAS-2B cell proliferation and LPS-induced $N F-\kappa B$ pathway activity. BEAS-2B cells were treated with HDW $(20,10,1$ or $0.1 \mu \mathrm{mol} / 1)$ for $1 \mathrm{~h}$ and challenged with

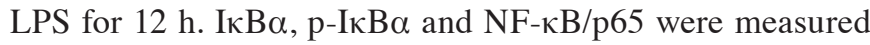
using western blotting. LPS treatment markedly upregulated the expression of $\mathrm{p}-\mathrm{I} \kappa \mathrm{B} \alpha$ and downregulated the expression of I $\kappa \mathrm{B} \alpha$ and NF- $\kappa \mathrm{B} / \mathrm{p} 65$, respectively (Fig. $5 \mathrm{~A}$ and B). These results suggest that the NF- $\mathrm{KB}$ signaling pathway may serve a role in the anti-inflammatory effect of HDW on airway-derived epithelial inflammation. 

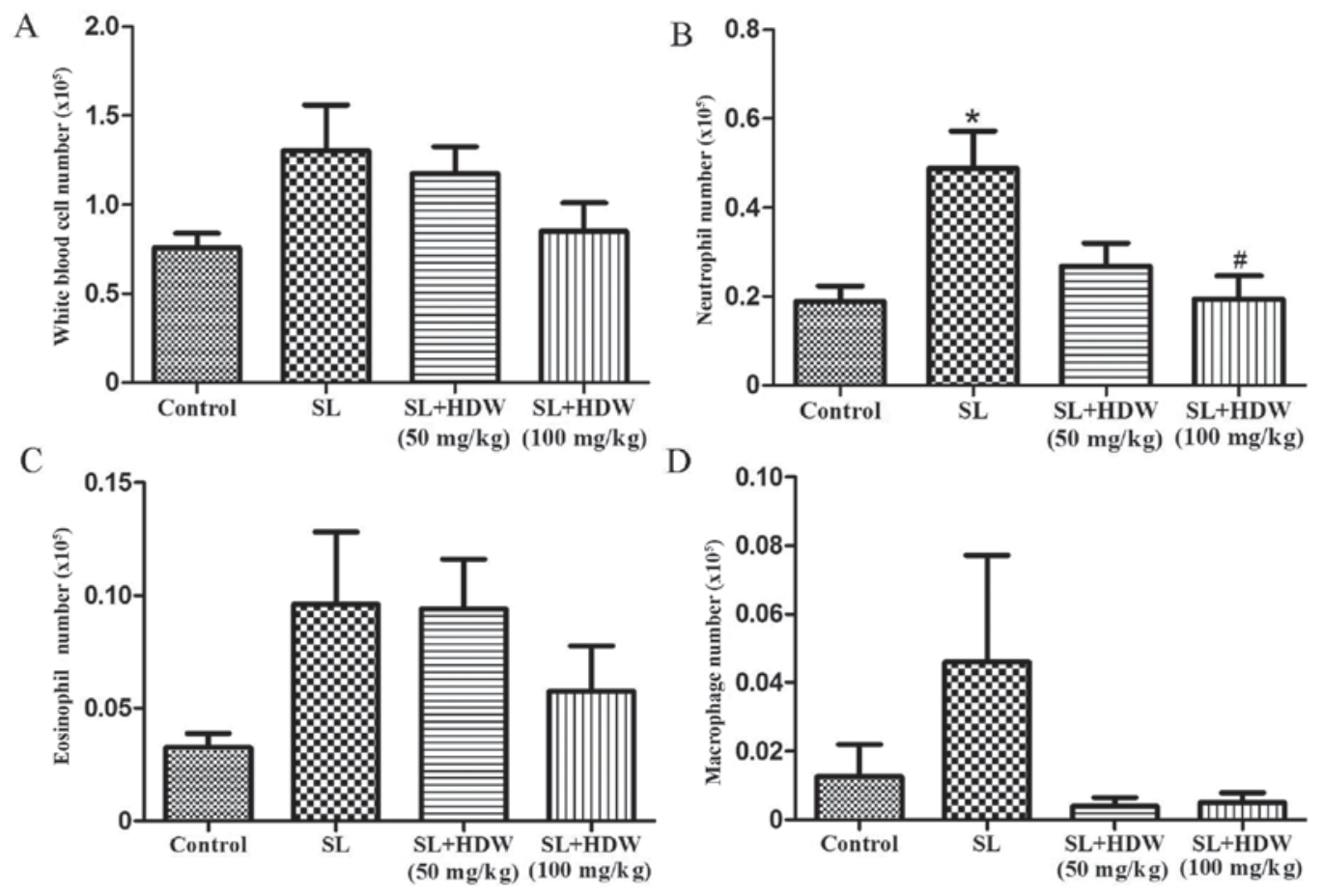

Figure 3. Effect of HDW on inflammatory cells in BALF. BALF was harvested from mice $24 \mathrm{~h}$ following final SL stimulus and the number of inflammatory cells was counted. (A) Total white blood cell count, (B) neutrophil count (C) eosinophil count and (D) macrophage count. ${ }^{*} \mathrm{P}<0.05 \mathrm{vs}$. control and ${ }^{\#} \mathrm{P}<0.05$ vs. SL. Control, saline-treated mice; SL, cigarette smoke+lipopolysaccharide-challenged mice; HDW, Hedyotis diffusa Willd; BALF, bronchoalveolar lavage fluid; DEX, dexamethasone $(1 \mathrm{mg} / \mathrm{kg})$.
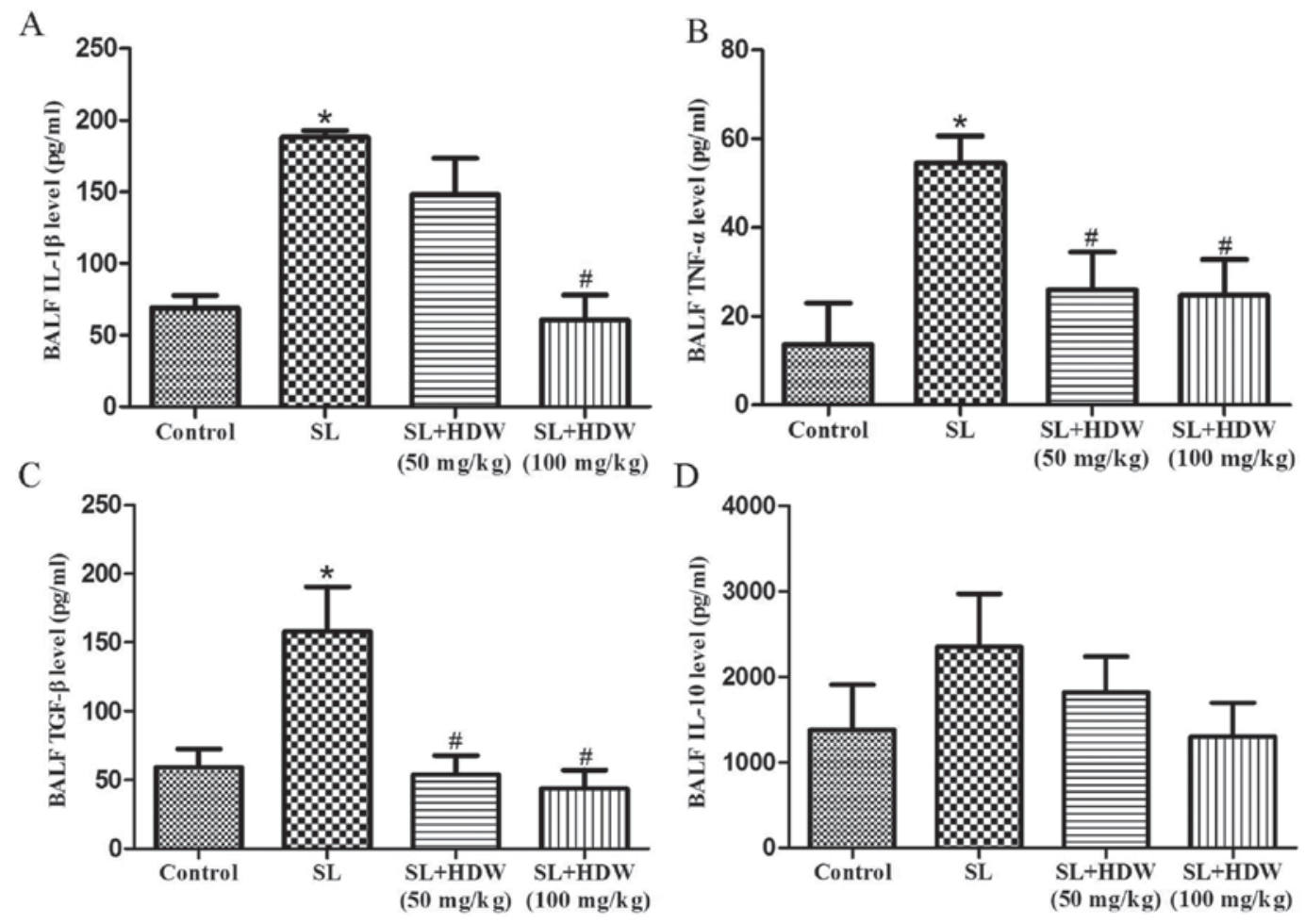

Figure 4. Effect of HDW on cytokine levels in BALF. BALF was harvested from mice $24 \mathrm{~h}$ following final SL stimulus and centrifuged to obtain the supernatant. Levels of (A) IL-1 $\beta$, (B) TNF- $\alpha$, (C) TGF- $\beta$ in BALF and (D) IL-10 in BALF were measured using ELISA. *P $<0.05$ vs. control and " $\mathrm{P}<0.05$ vs. SL. Control, saline-treated mice; SL, cigarette smoke+lipopolysaccharide-challenged mice; HDW, Hedyotis diffusa Willd; BALF, bronchoalveolar lavage fluid; DEX, dexamethasone $(1 \mathrm{mg} / \mathrm{kg})$.

BEAS-2B cells were treated with HDW in vitro. Cell proliferation inhibition was measured using a CCK8 assay. BEAS-2B cells were pretreated with $0.1,1$ or $10 \mu \mathrm{mol} / 1 \mathrm{HDW}$ for $24 \mathrm{~h}$ and the resulting $\mathrm{IC}_{50}$ value was $9.05 \mu \mathrm{mol} / 1$. As shown in Fig. 5C, when the HDW concentration was raised to 1 or $10 \mu \mathrm{mol} / 1$, the inhibition rate was increased to 25 and 
A

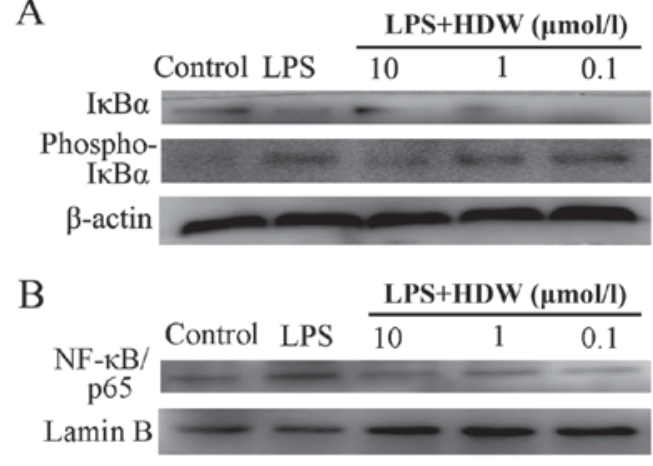

$\mathrm{C}$

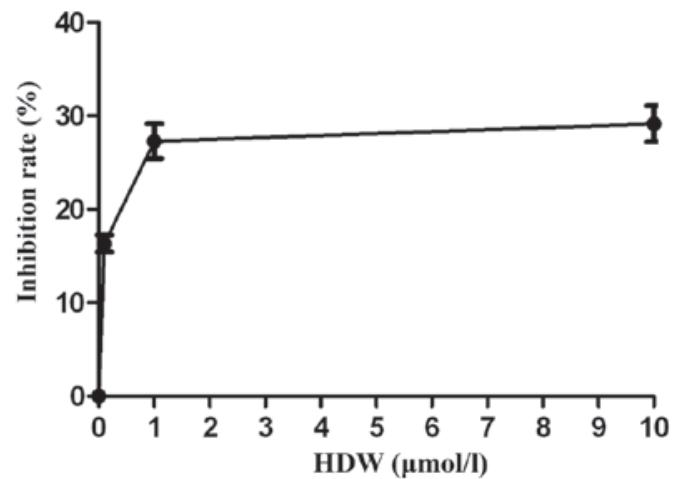

Figure 5. Effect of HDW on NF- $\mathrm{B}$ activity and cellular proliferation in BEAS-2B cells. (A) Cells were pretreated with HDW (20, 10,1 or $0.1 \mu$ mol/1) for $1 \mathrm{~h}$ and then treated with LPS $(10 \mu \mathrm{g} / \mathrm{ml})$ or D-Hanks for $30 \mathrm{~min}$. Western blotting was performed to assess the phosphorylation of I $\mathrm{B} \alpha$. (B) Cells were pretreated with HDW $(20,10,1$ or $0.1 \mu \mathrm{mol} / 1)$ for $1 \mathrm{~h}$ and then treated with LPS $(10 \mu \mathrm{g} / \mathrm{ml})$ or D-Hanks for $24 \mathrm{~h}$. Western blotting was performed to assess nuclear NF- $\kappa$ B/p65 expression. (C) The inhibition rates of BEAS-2B cells treated with HDW (20, 10, 1 or 0.1 $\mu$ mol/1) were detected using Cell Counting Kit-8 assays.

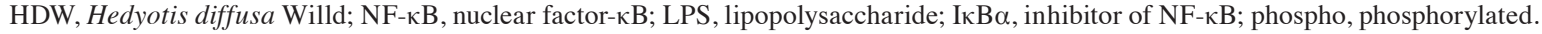

$31 \%$, respectively. HDW inhibited the growth of BEAS-2B cells.

\section{Discussion}

COPD is a chronic inflammatory disease characterized by progressive and irreversible airflow obstruction, chronic bronchitis, small airway remodeling and mucous overproduction (2). Cigarette smoking is considered to be a major cause of this disease. CS and LPS stimuli are used as a preclinical strategy for evaluating the main pathological characteristics of COPD (14). Consequently, a strategy combining CS and LPS stimuli was used in the present study to replicate the chronic inflammation associated with COPD. The COPD inflammatory pathway is characterized by elevated numbers of macrophages, neutrophils and lymphocytes (2). Cigarette smoking activates epithelial cells and macrophages to secrete inflammatory factors, which results in inflammatory cell recruitment and tissue damage (15). In the present study, the results demonstrate that HDW regulates cytokine (IL-1 $\beta$, TNF- $\alpha$, TGF- $\beta$ and IL-10) release in BALF. Histopathological examinations revealed that HDW suppresses inflammatory cell infiltration and airway remodeling compared with SL-induced mice. Furthermore, HDW decreased activation of the NF- $\mathrm{NB}$ signaling pathway. However, dexamethasone treatment in the present study had potent side effects, resulting in a decrease in spleen size and weight and body weight (in some mice, the thymus almost completely disappeared) in the dexamethasone treated group. Several mice succumbed during the experimental period.

The focus of the present study was the effect of HDW on chronic lung inflammation induced by SL. The effect of HDW on IL- $1 \beta$, TNF- $\alpha$, TGF- $\beta$ and IL-10 was assessed. These inflammatory cytokines are responsible for the inflammation observed in SL-challenged mice (16). Proinflammatory cytokines (TNF- $\alpha$ and IL-1 $\beta$ ) were upregulated in the BALF of mice with COPD increased the degree of airway inflammation, partly via $\mathrm{NF}-\kappa \mathrm{B}$ activation. In the present study, treating SL-challenged mice with HDW led to a decrease in lung IL-1 $\beta$ levels compared with SL-challenged mice. It has been reported that TNF- $\alpha$ induces and influx of inflammatory cells into the lungs, pulmonary fibrosis and emphysema in animal COPD models (17). TNF- $\alpha$ accelerates neutrophil migration by boosting the expression of IL- 8 and endothelial cell adhesion molecules (18). In vivo, increased levels of TNF- $\alpha$ in the BALF of patients are associated with stable COPD (18). In the present study, levels of TNF- $\alpha$ were increased in SL-induced mice compared with the untreated controls. However, treatment with HDW reduced the level of TNF- $\alpha$ in BALF. TGF- $\beta$ is a profibrotic cytokine that can be released by macrophages, epithelial cells, fibroblasts and eosinophils $(2,3,10)$. In the present study, treatment with HDW reduced TGF- $\beta$ expression in BALF and suppressed lung IL-10 levels compared with SL-challenged mice. $\mathrm{NF}-\kappa \mathrm{B}$ serves a significant role in lung pathology by regulating the expression of vital proinflammatory cytokines and chemokines (6). Upregulation of proinflammatory cytokines promotes cellular activation and enhances the infiltration of immune cells into airway tissues. The activation of $\mathrm{NF}-\kappa \mathrm{B}$ in COPD arises largely in response to the concerted action of inflammatory cytokines, including IL-1 $\beta$ and TNF- $\alpha$ (19).

Previous studies have been performed to evaluate whether crude extracts of HDW have potent antitumor activity $(13,20)$. Three major classes of HDW constituents, the ferulic, oleanolic and ursolic acids, have been identified as bioactive components of the herb. In the present study, HDW reduced the levels of IL-1 $\beta$, TNF- $\alpha$, TGF- $\beta$ and IL-10 in BALF and suppressed activation of the NF- $\mathrm{NB}$ pathway in an SL-challenged COPD mouse model. These findings provide further evidence that HDW may be a suitable treatment for COPD.

\section{Acknowledgements}

The authors thank Dr Jinlong Chen for the extraction and isolation of plant material. The authors also thank Mr. Fan Liu for performing HPLC-MS analysis.

\section{Funding}

The present study was supported by the Department of Science and Technology Program Funds of Jiangxi Province, China (grant nos. 20142BAB205001 and 20151BAB205085). 


\section{Availability of data and materials}

The analyzed data sets generated during the present study are available from the corresponding author on reasonable request.

\section{Authors' contributions}

RL contributed in the conception and design and revision of the manuscript, the acquisition, analysis and interpretation of data, and helped perform the animal and cell biology experiments. PW prepared the initial draft of the manuscript, contributed in the acquisition, analysis and interpretation of data, and helped perform the animal and cell biology experiments. CW, JC, CL, YX and QW contributed in the acquisition, analysis and interpretation of data, and helped perform the animal and cell biology experiments. JL, HH and JZ helped revise the manuscript and performed the histology and immunohistochemistry experiments.

\section{Ethics approval and consent to participate}

All protocols involving mice were approved by the Institutional Animal Experimental Ethics Committee of Nanchang University (Nanchang, China).

\section{Consent for publication}

Approved.

\section{Competing interests}

The authors declare that they have no competing interests.

\section{References}

1. Mathers $C$ and Loncar D: Projections of global mortality and burden of disease from 2002 to 2030. PLoS Med 3: e442, 2006.

2. Chen J, Yang X, Zhang W, Peng D, Xia Y, Lu Y, Han X, Song G, Zhu J and Liu R: Therapeutic effects of resveratrol in a mouse model of LPS and cigarette smoke-induced COPD. Inflammation 39: 1949-1959, 2016.

3. Chen J, Zhou H, Wang J, Zhang B, Liu F, Huang J, Li J, Lin J, Bai J and Liu R: Therapeutic effects of resveratrol in a mouse model of HDM-induced allergic asthma. Int Immunopharmacol 25: 43-48, 2015.

4. MacNee W: Pathogenesis of chronic obstructive pulmonary disease. Proc Am Thorac Soc 2: 258-266; discussion 290-291, 2005

5. Culpitt SV, Rogers DF, Shah P, De Matos C, Russell RE, Donnelly LE and Barnes PJ: Impaired inhibition by dexamethasone of cytokine release by alveolar macrophages from patients with chronic obstructive pulmonary disease. Am J Respir Crit Care Med 167: 24-31, 2003.
6. Liu R, Bai J, Xu G, Xuan L, Zhang T, Meng A and Hou Q: Multi-allergen challenge stimulates steriod-resistant airway inflammation via NF- $\mathrm{BB}$-mediated IL-8 expression. Inflammation 36: 845-854, 2013.

7. Choi IW, Sun K, Kim YS, Ko HM, Im SY, Kim JH, You HJ, Lee YC, Lee JH, Park YM and Lee HK: TNF-alpha induces the late-phase airway hyperresponsiveness and airway inflammation through cytosolic phospholipase A(2) activation. J Allergy Clin Immunol 116: 537-543, 2005

8. Wan YY and Flavell RA: Regulatory T cells, transforming growth factor-beta, and immune suppression. Proc Am Thorac Soc 4: 271-276, 2007.

9. Wang $\mathrm{H}$, Peng W, Weng Y, Ying $\mathrm{H}$, Li H, Xia D and $\mathrm{Yu} \mathrm{W}$ : Imbalance of Th17/Treg cells in mice with chronic cigarette smoke exposure. Int Immunopharmacol 14: 504-512, 2012.

10. Sutliff RL, Kang BY and Hart CM: PPARgamma as a potential therapeutic target in pulmonary hypertension. Ther Adv Respir Dis 4: 143-160, 2010.

11. Zhu H, Liang QH, Xiong XG, Chen J, Wu D, Wang Y, Yang B, Zhang Y, Zhang Y and Huang X: Anti-inflammatory effects of the bioactive compound ferulic acid contained in oldenlandia diffusa on collagen-induced arthritis in rats. Evid Based Complement Alternat Med 2014: 573801, 2014.

12. CaiQ,Lin J, WeiL,Zhang L, Wang L,Zhan Y,Zeng J,Xu W, Shen A, Hong $\mathrm{Z}$ and Peng J: Hedyotis diffusa Willd inhibits colorectal cancer growth in vivo via inhibition of STAT3 signaling pathway. Int J Mol Sci 13: 6117-6128, 2012.

13. Cipollina C, Di Vincenzo S, Gerbino S, Siena L, Gjomarkaj M and Pace E: Dual anti-oxidant and anti-inflammatory actions of the electrophilic cyclooxygenase-2-derived 17-oxo-DHA in lipopolysaccharide- and cigarette smoke-induced inflammation. Biochim Biophys Acta 1840: 2299-2309, 2014.

14. Herr C, Han G, Li D, Tschernig T, Dinh QT, Beißwenger C and Bals R: Combined exposure to bacteria and cigarette smoke resembles characteristic phenotypes of human COPD in a murine disease model. Exp Toxicol Pathol 67: 261-269, 2015.

15. Özdemir ÖM, Gözkeser E, Bir F and Yenisey C: The effects of resveratrol on hyperoxia-induced lung injury in neonatal rats. Pediatr Neonatol 55: 352-357, 2014.

16. Churg A, Cosio M and Wright JL: Mechanisms of cigarette smoke-induced COPD: Insights from animal models. Am J Physiol Lung Cell Mol Physiol 294: L612-L631, 2008.

17. Lundblad LK, Thompson-Figueroa J, Leclair T, Sullivan MJ, Poynter ME, Irvin CG and Bates JH: Tumor necrosis factor-alpha overexpression in lung disease: A single cause behind a complex phenotype. Am J Respir Crit Care Med 171: 1363-1370, 2005.

18. King PT: Inflammation in chronic obstructive pulmonary disease and its role in cardiovascular disease and lung cancer. Clin Transl Med 4: 68, 2015.

19. Edwards MR, Bartlett NW, Clarke D, Birrell M, Belvisi M and Johnston SL: Targeting the NF-kappaB pathway in asthma and chronic obstructive pulmonary disease. Pharmacol Ther 121: $1-13,2009$

20. Liu Z, Liu M, Liu M and Li J: Methylanthraquinone from Hedyotis diffusa WILLD induces $\mathrm{Ca}(2+)$-mediated apoptosis in human breast cancer cells. Toxicol In Vitro 24: 142-147, 2010.

This work is licensed under a Creative Commons Attribution-NonCommercial-NoDerivatives 4.0 International (CC BY-NC-ND 4.0) License. 